\title{
From Children's Perspectives: A Model of Aesthetic Processing in Theatre
}

\author{
JEANNE KLEIN
}

Since the children's theatre movement began, producers have sought to create artistic theatre experiences that best correspond to the adult-constructed aesthetic "needs" of young audiences by categorizing common differences according to age groups. For decades, directors simply chose plays on the basis of dramatic genres (e.g., fairy tales), as defined by children's presupposed interests or "tastes," by subscribing to Winifred Ward's broad descriptions of the "imaginative period" (ages six to nine), the "heroic period" (ages nine to twelve), and the "romantic period" (over age thirteen). ${ }^{1}$ Years later, Moses Goldberg elaborated upon these generalized divisions while cautioning that "no individual fits exactly into any set of categories." ${ }^{2}$ In his position paper on aesthetic development, he argued for individual access to aesthetic techniques, processes, and products for all ages, paralleled by four stages of cognitive capabilities, based on exposure to (1) arena-style participation theatre (for ages five to eight), which emphasizes story enactments; (2) a wide range of proscenium-style theatrical conventions; (3) relevant play content that directly relates characters' problems to spectators' lives and growing self-awareness; and (4) social issue plays that pose ethical dilemmas as cultural reflections. ${ }^{3}$ Meanwhile, Jed Davis compiled Age Group Profiles, organized by cognitive, spatial, emotional, and moral/ethical development, from his review of Piagetian literature; and Johnny Saldaña summarized stages of young interpretations of theatre from his seven-year longitudinal study. ${ }^{4}$

Suffice it to say, the field of developmental psychology has come a long way since Piaget formulated his four constructivist stages. Since the mid1950s, the cognitive revolution has spurred more integrated theories of information processing and depth-of-processing models that explain and predict how people construct schematic frameworks of knowledge and

Jeanne Klein is Associate Professor and Director of Theatre for Young People at the University of Kansas. Her recent publications include "ASSITEJ/USA Timeline" in TYA Today and "Children's Interpretations of Computer-Animated Dinosaurs in Theatre" in Youth Theatre Journal. In 2004 she directed Still Life with Iris, by Steven Dietz, and Really Rosie, by Maurice Sendak, music by Carole King. 
assimilate and accommodate new information as a function of perception, attention, emotion, comprehension, memory, and social and moral behaviors. Although masculinist metaphors of hierarchical "staircases" and linear networks of associative learning still dominate computational models, feminist perspectives, which engender social cognitive, co-relational negotiations of narratives in situated contexts, have gained more widespread acceptanceby including theatre as an apt metaphor for development. ${ }^{5}$ Over the past twenty years or more, cognitive psychologists have finally discovered what dramatic theorists have known about narrative structures since Aristotle's Poetics: Powerful stories contain universal themes about the human condition through characters' conflicting actions. The most successful dramas are those that allow spectators to enter into a protagonist's psychological consciousness or "inner" vision in order to empathize with her "outer" reality. ${ }^{6}$

While several developmental models of aesthetic understanding, experience, and appreciation exist in the realms of visual art and music education, few examples have been proposed in regard to theatre, particularly for child audiences. ${ }^{7}$ Instead, producers of Theatre for Young Audiences (TYA) tend to romanticize its social and moral "effects" upon youth by believing passionately that viewing one remarkable performance has the potential (the operative word) to "cause" positive, social changes in children's minds, hearts, and behaviors, given the presumed "power of human imagination." ${ }^{8}$ This obsession with progressive change foregrounds adults' desires to control human destiny by predicting "causes and effects" located in children's responses to live performances. However, this "folk theory" fails to explain how young imaginations actually function aesthetically from the contextual evidence of reception studies with child audiences. Just as feminists have argued for a distinctive "feminist aesthetics," based on women's alternative ways of knowing, ${ }^{9}$ I argue that children gaze upon theatre in differential ways by including age as a variable factor. "Children's aesthetics," their perceived interpretations of theatre, differ from that of adults' theorized postulations, based in part on their shorter life experiences with this medium. To this end, over the course of my career, I have sought to understand theatre from children's perspectives by focusing my research in the social cognitive theories and social science methods of child development, primarily through the vast literature of television and mass media studies conducted with young people over the past forty years. In particular, medium-specific studies that parse theatrical forms from dramatic content have guided my work for comparative purposes.

Although media researchers have yet to explore how distinctive aesthetic tastes are formed during childhood, young audiences increasingly voice sophisticated criticisms of mass media entertainment and educational programming as a function of age and gender differences. ${ }^{10}$ On television, they choose to watch educationally defined "prosocial" narratives, with 
humor-embedded, social-emotional themes that deal with their issues realistically, over academic programs that explicitly teach curricular lessons. Girls and second- to fourth-graders prefer narrative stories more than boys and older fifth- and sixth-graders, who gradually lose interest as they engage in alternative activities (e.g., video games, computers, and sports). While animated programs draw more viewers than "live" comedies and dramas, girls prefer living actors as a reflection of their greater interests in social relationships more than boys. ${ }^{11}$ This finding adds weight to the unproven hypothesis that the theatre medium and its live actors may engage girls' more than boys' aesthetic pleasures best. ${ }^{12}$

Given these cultivated tastes in mass media, I have been investigating the following broad question: How do children experience theatre as an aesthetic medium by making meanings of scripted plays in live performances? The medium of theatre constitutes a complex amalgam of all art forms in which artists visualize and vocalize their subjective interpretations of textual language as metaphors of representation. From a Langerian perspective, each artistic form or semiotic element expresses and arouses "virtual feelings" of aesthetic experiences in spectators who feed back cyclical loops of communication through their shared presence. Yet how and when (i.e., at what age and under what conditions) do young spectators simultaneously feel and abstract imagistic forms and their conceptual, metaphorical content beyond discursive means? For, as Susanne Langer asserts, "It is characteristic of figurative images that their allegorical status is not recognized. Only a mind which can appreciate both a literal and a 'poetic' formulation of an idea is in a position to distinguish the figure from its meaning. In spontaneous envisagement, there is no such duality of form and content."13 Therefore, I define the imaginative "aesthetic experience" as an internal cognitive-affective process of intra- and interpersonal meaning making, which occurs during performances, and an external product of judgmental response, as expressed verbally after performances. ${ }^{14}$ Furthermore, I maintain that children's presupposed "inability" to articulate their aesthetic experiences through discursive language in post-performance conversations should not impede our objective interpretations of their subjectivities, for we simply need more clever, behavioral methods of drawing out their experiential knowledge. $^{15}$

What follows is my integrated literature review of multiple models of information processing as applied to theatre spectatorship before, during, and after performances (see Fig. 1). ${ }^{16}$ This proposed model seeks to explain (1) what kinds of meanings spectators make of scripted plays in performance; (2) how they derive individualized meanings by virtue of the "nature and nurture" principles of cognitive, affective, social, and moral development; and (3) the conditions under which theatre may have minimum-to-maximum aesthetic "effects" or personally rewarding gratifications. I visualize 


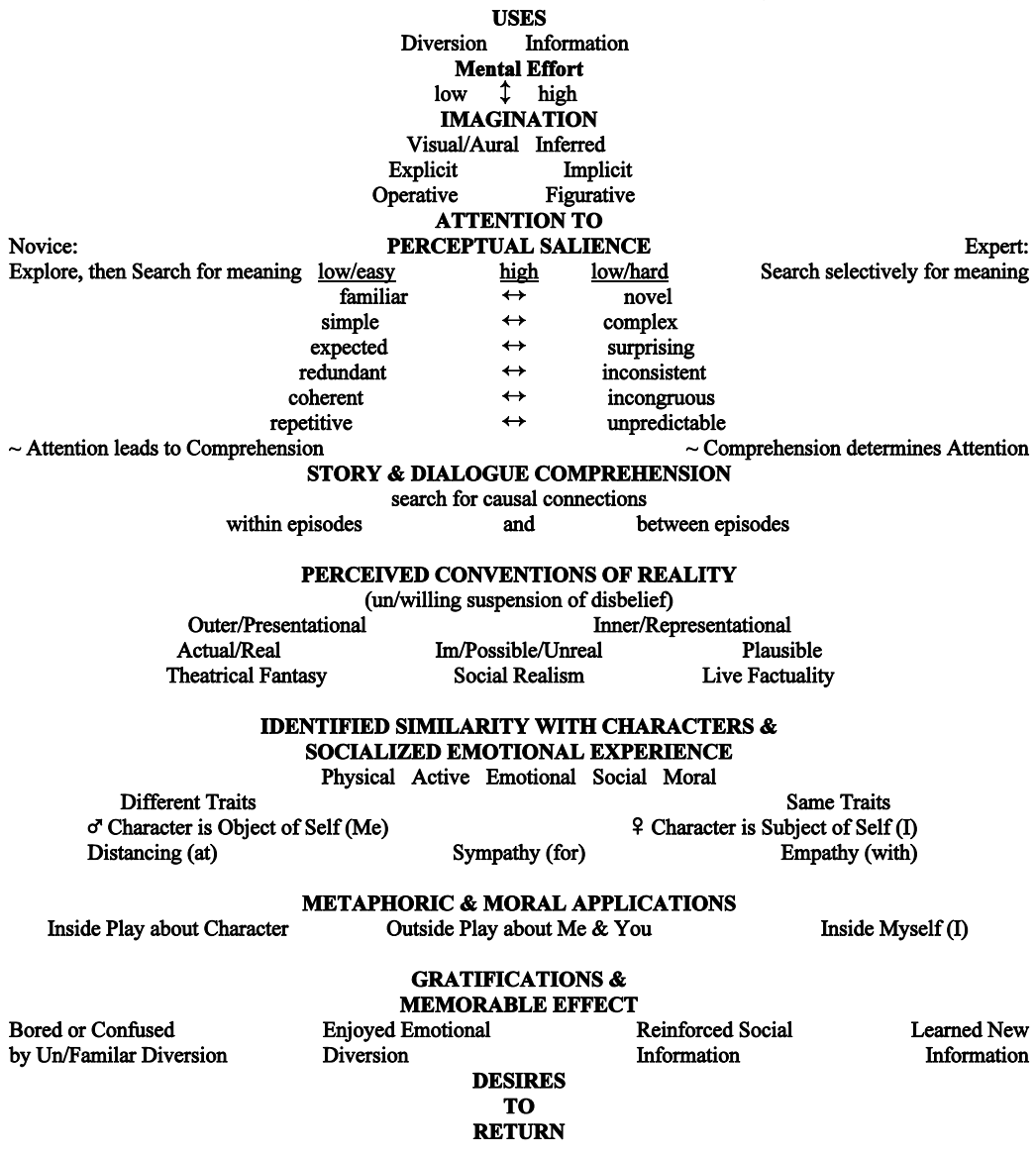

NO, can enjoy/learn through other activities

YES, to learn/enjoy through theatre

Figure 1. Tree of Aesthetic Processing.

this top-down model of simultaneous processing as a tree image to suggest ongoing growth, with each horizontal branch depicting a continuum of individual and developmental differences (from left to right). In regard to consequential behaviors after performances, I ground this ever-green image in spectators' potential desires to return to theatre in the future, for we can never know whether the messages of a one- to two-hour performance actually "change" attitudes or behaviors, given access to alternative aesthetic experiences in mass media.

This aesthetic model offers a way of explicating in categorical detail what many artists and educators may take for granted, while focusing upon middle childhood (ages six to twelve) when most youngsters attend theatre as school field trips. However, rather than conceive this model as strictly 
developmental around age constructs, the concepts provided here should be construed according to Vygotsky's novice-expert model of learning. In other words, adolescents and adults who have not yet experienced a comprehensive theatre education (e.g., teachers, parents, and students in introductory courses) may also be positioned as novice spectators who have yet to grasp fully how theatre's semiotic elements function holistically and metaphorically. I also predicate this model on the assumption that each individual spectator has personal agency when making cognitive and socialized decisions, and that resulting interpretations of performances may both match and/or differ from producers' artistic intentions.

Most theoretical discussions focus upon what plays and performances bring to audiences; this model accentuates what young audiences bring to theatrical events. Children do not come to theatre as tabulae rasae (blank slates), upon which plays imprint "new" ideas in their minds and hearts, but as already complete human beings with multifarious experiences and knowledge about theatre and life itself. By age six, they have already constructed basic story schemas for drama, having role-played their own scripts in pretend play since age three; and they know many theatrical conventions from watching television and film. Contrary to assumptions that epistemological development stays an upward, curvilinear course during the elementary years, drama skills and theatre apprehensions more likely develop in "streams, waves, and channels of symbolization" in a more undulating, U-shaped fashion. ${ }^{17}$

\section{Causal Uses and Gratification Effects}

So much of what audiences derive from performances depends, first of all, on personal motivations for viewing and listening; that is, how each individual intends to use the theatrical event for his or her purposes and for what expected gratifications. ${ }^{18}$ Ritualistic viewers seek diverting entertainment as an escape or withdrawal from daily concerns by watching media "passively" out of habit, although their minds are still quite actively processing information. In contrast, instrumental viewers actively seek further education by expecting to learn social information of specific interest to their personal identities, in relation to characters' dramatized situations, which they may discuss with friends. Respective gratifications also determine whether viewers will use theatre to search for and find ideas that already fit into or differ from their current beliefs and values according to individual biases and aesthetic "tastes."

"Kidnapped" school audiences seldom choose to attend a matinee performance, because teachers have already decided for them. Given this context, some students may come expecting to learn some information ostensibly connected with their curricula, while others may relish an escape from 
their school buildings and daily routines. Whether theatre is "necessary" to their lives depends on their preconceptions of these utilitarian purposes. ${ }^{19}$ Likewise, their teachers' uses of theatre (i.e., for pure entertainment without further discussion or for pre- and post-show curricular extensions) will also impinge upon students' utilitarian choices. ${ }^{20}$ Furthermore, emotional mood predispositions (e.g., excitation, sleep deprivation) at the time of viewing also affect uses-and-gratifications decisions. ${ }^{21}$

\section{Amount of Invested Mental Effort}

After expecting to gaze upon a performance for fun (entertaining diversion) and/or for learning (educational information), individuals then decide how much mental effort they are willing to invest in making sense of the performance. Instrumental viewers invest far more mindful mental effort than ritualistic viewers who tend to process information automatically (hence, "passively") by relying on past schemas of experiential knowledge. Degrees of mindfulness, then, determine all subsequent processes of meaning making.

To test Marshall McLuhan's hypothesis that the "medium is the message," comparative media studies find that young viewers' perceptions of a medium's cognitive demands and their own self-efficacy in understanding messages, as well as extrinsic and intrinsic motivations and rewards for learning, also impact mental effort and comprehension. When sixth-graders perceive that the audiovisual medium of television is easier to follow than reading the same content in print, they don't invest sufficient mental effort, they generate less mental elaborations and inferences, and they fail to comprehend material at higher levels of learning-even if they are already high academic achievers. However, when instructed to learn from television before viewing, rather than watching for fun, they do invest significantly more mental effort, as demonstrated by greater comprehension, in comparison to reading print. $^{22}$

Do young spectators perceive the medium of theatre as "easy" to understand for its readily available audiovisual forms and, therefore, less worthy of invested mental effort, or "harder" to understand than television, given its lack of camera-directed, close-up shots and more abstract scenography? We simply don't know, for no one to date has compared learning from these two media with matched content. Yet when mindful teachers instruct students to watch theatre for purposeful learning by preparing them for attendance with pre-show activities from study guides, even ritualistic viewers may be more likely to invest sufficient mental effort and gain alternative gratifications from post-show discussions. However, if pre-performance learning (e.g., knowing the play's synopsis) removes all surprises and suspense from the drama they are to watch, then viewing may become simply 
a comparative exercise of previously learned information. For example, if students read or preview original sources of dramatic adaptations, then the only remaining surprise may be wondering how artists will realize the drama in comparison to book or movie versions. ${ }^{23}$

In sum, if spectators expect to use theatre solely for entertainment and process ideas with low mental effort by following the left side of the tree model, they may experience boredom or confusion as a consequence. If, on the other hand, they use theatre to gain personally relevant information by investing high mental effort and following the right side of the tree, they may learn new concepts by integrating such messages into their schemas of knowledge.

\section{Sensory Imagery and Imagination as Cognition}

One of the biggest, ongoing myths about children's minds is that they have vast imaginations whereby they "fill in" missing imagery on stage; however, the opposite tends to be true more often than not for many ritualistic viewers. For example, even fifth-graders tend to ignore off-stage characters and dramatic actions discussed only in dialogue. ${ }^{24}$ Child audiences are "concrete" (literal) processors who focus on seeing the explicit visual images and hearing the explicit verbal dialogue presented to them. Any information that isn't concrete and actualized on stage must be inferred from implicit, contextual clues. Not until age eight or so do they realize that inferences need to be made from characters perspectives that differ from their own egocentric viewpoints, and thereafter, this ability to draw inferences from psychological modalities increases with age. With sufficient mental effort, the more youngsters attend to visual and verbal/aural images, the more they make psychological inferences about characters' unstated objectives, motivations, and decisive actions. Playwrights who do not trust their inferencemaking abilities tend to include "preachy" dialogue that explains and repeats symbolic (educational) information to be sure they "get" intended messages. For some children, this verbal labeling of visualized actions assists their comprehension efforts, while for others, redundant dialogue only serves to turn them off toward academic instruction.

\section{Attention to Perceptually Salient Features}

Another major myth concerns the notion that children have "weak" attention spans, when in fact their attentions are as variable and complex as adults' attentions. This false premise derives from adults watching young behaviors and assuming their restlessness means [fill in the blank]. Yet adults, too, often stop paying attention to performances, but they control their impatience quietly without distracting other audience members. 
The process of attention is guided by individual decisions to explore and search for information. Young children and novice spectators first explore unfamiliar images and concepts before searching for specific meanings crucial to comprehension. In other words, explorative attention to semiotic elements leads to comprehension. In contrast, older children and experienced theatregoers search selectively only for those meanings they need to accommodate their existing schemas. Thus, comprehension determines the attention one continues to give at any moment during performances.

These processes are depicted in a helpful Traveling Lens Model, which explains how attentions vary as a function of perceptual salience within a medium's formal features. ${ }^{25}$ The accompanying comprehensibility hypothesis predicts how children (and adults) use salient forms to signal attention, comprehensibility, and interest. That is, children will attend to that content they expect to understand and will work to understand it, especially if the information interests them personally. For example, if a performance contains simple, familiar, expected, redundant, and coherent images and concepts, viewers will turn off, grow bored and restless, and stop investing mental effort for comprehension. At the other end of these continua, if spectators perceive the performance's features as too novel, complex, surprising, inconsistent, incongruous, and completely unpredictable, children (and teachers) may give up trying to make sense of its absurdity and blame the production for "going over their heads," rather than attributing difficulties to their own lack of mental effort, persistence, and self-efficacy. When the salience of performance features (both form and content) is balanced between these two extremes, degrees of attention and comprehension optimize learning.

\section{Story Comprehension: Dramatic Actions and Dialogue}

Dramatic actions, what characters do and say on stage, are the primary vehicles by which audiences make meanings of stories. Dramatic action should not be confused with incidental, physical activity and indicative movement, but defined by characters' central, plot-driven objectives that signify, rather than merely represent, their psychological motives-crucial distinctions when interpreting post-performance responses.

Story schemas drive preferences for linear narratives as children search for cause-and-effect actions within plot structures. Spectators as young as six are able to find linear chains within so-called "absurdist" plays involving one basic situation. ${ }^{26}$ Depending on the continuity and complexity of dramatic structures, developmental abilities shift from focusing on concrete actions and causal connections within episodic scenes (ages four to nine) to between episodes (by age ten) as readers increasingly focus on characters' internally motivated goals to interpret overarching themes. ${ }^{27}$ Flashbacks 
and dream sequences, which require inter-episodic connections, may confuse young children as incoherent or odd replays. Contrary to assumptions that children require fast-paced staging to "hold their attentions," primarygrade students need tempos slow enough to make temporal connections between actions, motives, and consequences in tune with developmental speeds of processing. ${ }^{28}$

\section{Perceived Conventions of Reality}

Much has been made of children's "failure" to distinguish fantasy from reality (an ability achieved between ages four and seven), especially as the lines of reality grow increasingly blurred in mass media. Whether informational facts and news events are actually "true or false" matters less than people's perceptions of truth and fiction, especially when primed to believe that a given story is "based" on actual, past events. Perceptions of reality are particularly crucial in middle childhood - the stage of literal realismbecause all forms of operative and figurative re/presentation are compared and judged against the actual reality of life experiences according to selfprescribed rules of realism readily available to all for evaluation purposes.

Regardless of theatrical frameworks intended by artists, viewers control aesthetic distance idiosyncratically by their decisions on whether to focus upon the theatrical delusions of outer presentational forms of the production (i.e., acting, staging, and design techniques) and/or the dramatic illusions of inner representational content of fictional dramas at specific moments throughout performances. ${ }^{29}$ For example, youngsters often search for the technical causes of theatrical effects (e.g., watching a mirror ball to see how fragmented lights work). Even viewers focused inside representations still want to see actual images (e.g., standing up to see "invisible" footprints on the stage floor).

Developmentally, novice audiences judge degrees of reality and factuality, first, by comparing the external, physical appearances of images against the actual phenomenal world (i.e., photographic realism) and by attributing fantastical characteristics to the artistic tricks of the medium and its technology. Around age nine, as they begin to infer artists' intentions, they judge the possibilities of dramatized situations in comparison to believable psychosocial behaviors and rules of social realism. By age twelve, they discern the plausibility of dramatic texts like French neoclassicists by criticizing any exaggerations of character decorum and by scrutinizing theatrical elements for implausible degrees of distortion and sensationalism. ${ }^{30}$ Thus, in keeping with U-shaped models of aesthetic development, primary-grade students find pleasure in expressionist fantasies that intermediate-grade students (and teachers) may reject as too unbelievable, unrealistic, incomprehensible, or avant-garde. Regardless of age, spectators choose whether to "suspend 
their disbelief"-willingly or not-especially when ritualistic viewers focus on finding illogical actions that counter their rules of social realism. ${ }^{31}$

\section{Identifications with Characters and Socialized Emotional Experiences}

Theatre producers have long assumed that children automatically "identify" with stage characters through empathic bonds by comparing characters' identities against their own perceived selves (who I think I am), projected selves (who others think I am), or idealized selves (who I wish to become) and then adopting characters' modeled behaviors. ${ }^{32}$ Bandura's social cognitive (learning) theory predicts that children learn by observing and imitating role-modeled behaviors based on consequentially reinforced rewards and punishments (behaviorism). However, role-modeling involves a complex network of self-reflective and self-regulatory decision making all dependent upon attention, retention, production, and motivational processes. ${ }^{33}$

Accordingly, another Message Interpretation Process model explains a causal sequence whereby observers first determine social realism by whether a character portrayal appears socially normative (like most people I know). If perceived as realistic, then viewers go on to judge how similar a character's identifiable traits are in relation to personal experiences. Developmentally, children attend to physical appearances and shared, favorite activities before comparing themselves with characters' emotional, social, and moral traits. If characters survive this perceived similarity "test," then viewers may identify with attractive characters and want to be like these ideals (or idols). If they feel highly capable of assuming the character's identity (e.g., wearing the same fashions) or performing the same activities (e.g., name-calling) and they expect to achieve the same rewarded consequences as the character, then they may likely adopt the character's prosocial and/or antisocial behaviors in similar situations. However, while behavioral effects most often occur in the immediate, short-term (right after performances) in the form of behavioral activities (i.e., the imitative model), the adoption of long-lasting behavioral actions more likely appear over the long term of development. In addition, decisions to change attitudes and future behavioral actions are mediated by desires for peer approval and conformity to peer pressures, as well as parents and teachers who cultivate critical skepticism about the perceived realities of media messages. ${ }^{34}$

Vicarious identifications with characters are intrinsically connected with socialized and gendered emotional responses, which also depend on whether spectators perceive characters as objects of themselves (Me) or as subjects of themselves (I). Developmentally, the younger Me-self focuses on egocentric comparisons, whereas the older I-self actively constructs meta-cognitive distinctions separate from others. As perspective-taking abilities increase with 
age, the I-self evaluates the Me-self by shifting self-criticisms from external social standards to internalized mores that reflect personal beliefs. These conceptual differences are particularly crucial when explaining how children develop self-awareness of their growing identities. ${ }^{35}$

During performances, emotional responses vary considerably by age and gender, as spectators grow acquainted with characters in context-specific situations. Degrees of cognitive-affective connectedness change constantly as viewers both think and feel with (empathy), for (sympathy), or at (distancing) characters' thought- and action-driven emotions. While empathy and sympathy are processed from within representational illusions, distancing occurs when viewers focus on presentational delusions (e.g., laughing at adult actors ostensibly pretending to be child characters because one feels superior to them). Definitional distinctions between empathy (i.e., sharing the same thoughts and emotions) and sympathy (i.e., feeling the same emotion but for different cognitive reasons) are critical because empathy, and not necessarily sympathy, generates subsequent altruistic behaviors. While empathy depends on mutually shared connectedness, sympathy differs by degrees of comparative separations between self $(\mathrm{Me} / \mathrm{I})$ and characters in the forms of personal distress, projection, contagion, or vicarious role-taking. ${ }^{36}$

Gender plays a significant role in emotional responses, largely because girls focus more subjectively on interpersonal, character relationships than boys who attend objectively to technical production features. Because girls are socialized to express and verbalize their emotions more than boys, older girls empathize and sympathize by making I-self comparisons with characters' emotional traits more often than younger boys who tend to distance themselves with Me-self comparisons. Despite these gender differences, girls and boys are equally likely to behave prosocially, given their respective moral orientations of caring and justice. ${ }^{37}$

\section{Metaphoric and Moral Applications}

For me, the hallmark of aesthetic experience lies in spectators' recognition and articulation of metaphoric and moral applications of a play's themes to self and society. Asking youngsters to deduce a play's "main idea" (or lesson) from a one-hour-long performance poses a major cognitive challengean inferential ability sometimes not addressed in language arts curricula until the third grade (age eight). Asking what a protagonist learned (or decided to do) at the end of a play offers a more effective way of gathering open-ended interpretations to multifarious themes. Developmentally, typical responses range from re-descriptions of characters' dramatized actions inside plays to more abstract, global generalizations outside performed 
contexts that indicate analogous applications to spectators' lives (i.e., about Me and You or society at large). When individuals articulate those themes that resonate empathically inside themselves (I-self), these personal applications indicate virtual feelings of aesthetic experience and transfers of learning from inside representations to enriched knowledge about one's self.

Cumulative results from various reception studies make evident that the majority of young audiences interpret thematic concepts simply by recounting what characters said and did within performances (e.g., Pippi Longstocking learned that "staying with her friends is more important than sailing the seas with her father"). ${ }^{38}$ For these ritualistic viewers, characters' objectified situations, distanced "over there" on proscenium stages, may appear to have no relevant bearing on their personal lives. Alternatively, literal descriptions within play content may simply be much easier to deduce from readily available aural/visual images than drawing global inferences through inductive reasoning. For these reasons, only a minority of child spectators (about one-quarter to one-third), regardless of age, go beyond performance confines by abstracting universal themes about our human conditions, as indicated by using the words "you" or "people." These instrumental viewers articulate broad social themes by extrapolating generalizations from characters' actions (e.g., "Sometimes you have to make tough decisions between your friends and family"), by stating moral prescriptions for cooperative social behaviors (e.g., "People should not take their friends for granted"), or by projecting current knowledge from personal experiences outside the play's context (e.g., "I didn't want to leave my friends when we moved"). Although older children are more likely than younger ones to formulate themes in metaphoric terms, given their greater abilities to make temporal connections between episodic scenes, six-yearolds are not incapable of this formal operational ability (e.g., "You should keep your friends"). As shown by these examples, friendship, family relationships, and ethical behaviors foreground children's concerns when comparing metaphors between drama and life, largely because such "lessons" reflect developmental patterns of prosocial reasoning, emotional competence, and moral values. ${ }^{39}$

For these reasons, I argue that plays more likely affirm and reinforce conceptual ideas already learned than "teach" youngsters any "new" information that they don't already know and recognize. In other words, a child may abstract metaphoric applications because she already knows and has experienced the same analogous situations in her life; therefore, she has the ability to articulate such themes in post-performance conversations. Thus, we find ourselves caught in a theoretical conundrum: By producing plays in which children can (already) enter into protagonists' realities, we are simply replicating their current experiential knowledge. This factor then explains another reason for their restless, impatient behaviors during performances-been there, done that. Alternatively, if children are not able to 
interpret metaphoric concepts, then we might consider such performances "unsuccessful" from an educational standpoint.

Nevertheless, theatre practitioners hold fast to their beliefs that plays "educate" young people through the "glories" of theatre, without critically questioning alternative theoretical possibilities. Given that young children are still learning to infer causal connections, the temporal distance between any concepts "learned" after attendance and future analogous situations further decreases the chances of their remembering and applying such behavioral "lessons" in the future. The road to transfer of learning from performances to future behaviors is quite rocky, as is evident from many studies in various domains. ${ }^{40}$ Just because children can distinguish moral from immoral behaviors does not necessarily mean that they will transfer such "learning" to their own future behaviors. For these reasons combined, I contend that viewing theatre alone does not cause social changes in behaviors.

\section{Desires to Return}

Whether young audiences will return to theatre again depends, of course, upon whether their adult caretakers will take them to future productions. Even when adolescents obtain their drivers' licenses, few attend theatre voluntarily. Regardless of accessibility issues, individual desires to return to theatre depend primarily on the success or failure of respective gratifications and the corresponding aesthetic judgments made about each experience. Given the far greater availability of mass media than live theatre (in the privacy of technologically wired bedrooms no less! ${ }^{41}$ ), chances are much higher that young people will choose alternative means of diversion and information than theatre, even when offered the choice to attend again with their families.

Theatre lovers believe fervently that TYA creates future audiences. Yet this widespread "folk" myth has little basis in reality other than those urban centers that comprise a major TYA company and other thriving theatres (e.g., Minneapolis, Seattle, Chicago). National surveys of theatre attendance reveal that only a minority (12 percent to 18 percent) of primarily college-educated adults attend theatre about two or three times annually on average, especially those born before $1946 .{ }^{42}$ Recent surveys of estimated TYA attendance figures bloat the overlapping individuals who attend more than one production at the same theatre and at different touring venues annually. ${ }^{43}$ Without longitudinal studies that track the same individuals over time, we cannot know the actual number of young spectators who return to theatre in subsequent years and as adults. It remains to be seen whether teachers and parents of post-boomer generations, especially those raised on school field trips, will take their young people to theatre. Meanwhile, approximately one hundred professional TYA companies serve a U.S. youth population of over forty-one million. ${ }^{44}$ 


\section{Implications}

Unfortunately, this model does not matter to most TYA producers, for they don't choose and stage plays on the basis of audiences' aesthetic processing. Instead, seasons are selected by directors' tastes for adult-determined "meritorious" texts, production resources and budgets, and schools' curricula and local marketability. ${ }^{45}$ This is not to say that some of these reasons may not conjoin with developmental processing, but that children's ways of apprehending theatre are seldom the first priority of consideration during initial script analyses. Regardless of obvious age differences institutionalized by kindergarten through twelfth-grade levels, producers must market "age-appropriate" plays to combined grade levels and "popular titles" to euphemistically labeled "family" audiences. Yes, any play worthy of children ought to edify adults as well-but at whose expense? Shouldn't "children's theatre" and "theatre for young audiences" mean that children hold ownership of theatre first and foremost, above the peculiar interests of well-intentioned adults? I believe we need to entertain another possibilitythat we are raising generations of spectators who perceive theatre as an incomprehensibly abstract medium intended primarily for school field trips.

While intergenerational audiences enrich aesthetic experiences for all, I still wonder how a young child feels when she doesn't get the joke that makes others laugh so loudly. What about the child who conflates his own confusion with the protagonist's dream-state confusion? Without postperformance discussions in classrooms or at home, what happens to these misunderstandings and nascent concepts of theatre? Given that producers cannot rely upon teachers (and parents) to process performances for them, I maintain that all meaning making should come from the stage and not from study guides, just as we expect with television and film viewing. Until elementary schools include theatre curricula with drama specialists like art and music, we must ensure intended aesthetic comprehension and appreciation through performances alone.

Artists would argue that child psychology is not within their purviewtheir focus should remain exclusively on "creating art." We needn't worry about misapprehensions because children will comprehend whatever concepts are available to their cognitive capacities when they are individually and developmentally ready. Nevertheless, artists practice "folk" psychology each time they make misguided or erroneous assumptions about children's understandings of plays based solely on mis/interpretations of behavioral responses during performances, as discussed above. ${ }^{46}$ Is it no wonder then that directors are surprised when child audiences "fail" to behave "appropriately" by not grasping the theatrical conventions that artists take for granted ${ }^{47}$

There are no artistic formulas for creating meaningful productions that meet every individual's aesthetic process in every instance. However, 
contrary to the cognitive-readiness standpoint, artists can construct theatre more conducive to developmental apprehension through formative and summative research, just as the Children's Television Workshop has done for three decades. If directors want a new "vocabulary" to predict behavioral phenomena, they might employ the terminology provided herein before choosing plays. Questions of framing devices (e.g., a play within a play, flashbacks, direct address), perceived reality, and satire and irony must be tackled during production conferences and rehearsal processes from children's perspectives to communicate intended choices best. In these ways, we might enhance aesthetic experiences for a greater majority of young spectators by adjusting salient features accordingly before performance runs. Despite the uncontrollable and widely variable complexities of aesthetic processing inherent within this model, we may begin to better predict the otherwise unpredictable responses of young audiences from a more informed knowledge base.

\section{NOTES}

1. Winifred Ward, Theatre for Children (New York: Appleton-Century, 1939), 119-22. She also believed, "A series [of plays] for tiny children is unnecessary, for they do not need a theatre. Their own dramatic play is entirely satisfying, and, given wise parents and teachers to play with them, nurturing and encouraging their natural dramatic impulse, they will grow into understanding and appreciative audiences when they are older," 120.

2. Moses Goldberg, Children s Theatre: A Philosophy and a Method (Englewood Cliffs, N.J.: Prentice Hall, 1974), 80-84; and "An Experiment in Theatre for the 5-8 Year Olds," Children s Theatre Review 19, no. 3 (1970): 7-11, 18.

3. Moses Goldberg, "Aesthetic Development: A Position Paper," Children s Theatre Review 34, no. 1 (1985): 3-6. See also Bernard S. Rosenblatt, "A Theory for Curriculum for Theatre Education at the Elementary Grades," on developing "theatrical sensibility" in Children s Theatre Review 33, no. 2 (1984): 11-15.

4. Jed H. Davis and Mary Jane Evans, Theatre, Children and Youth (New Orleans: Anchorage Press, 1982), 59-71; Johnny Saldaña, "'Significant Differences' in Child Audience Response: Assertions from the ASU Longitudinal Study," Youth Theatre Journal 10 (1996): 81.

5. See drama masks in Ellin Kofsky Scholnick, "Engendering Development: Metaphors of Change,"in Toward a Feminist Developmental Psychology, ed. Patricia H. Miller and Ellin Kofsky Scholnick (New York: Routledge, 2000), 29-42.

6. Jerome Bruner, Actual Minds, Possible Worlds (Cambridge, Mass.: Harvard University Press, 1986), 21.

7. For example, see Michael J. Parsons, How We Understand Art: A Cognitive Developmental Account of Aesthetic Experience (Cambridge: Cambridge University Press, 1987); and Jeanne Bamberger, The Mind Behind the Musical Ear: How Children Develop Musical Intelligence (Cambridge, Mass.: Harvard University Press, 1991). Theatre models include Susan Bennett, Theatre Audiences: A Theory of Production and Reception (New York: Routledge, 1990), 183; and Willmar Sauter, The Theatrical Event (Iowa City: University of Iowa Press, 2000), 6-11. See also Monica Prendergast, "Playing Attention': Contemporary Aesthetics and Performing Arts Audience Education," Journal of Aesthetic Education 38, no. 3 (2004): 36-51. 
8. For example, see Peter C. Brosius, "Can Theater + Young People $=$ Social Change? The Answer Must Be Yes," Theater 31, no. 3 (2001): 74-75.

9. Karen Laughlin, "Introduction: Why Feminist Aesthetics?" in Theatre and Feminist Aesthetics, ed. Karen Laughlin and Catherine Schuler (Cranbury, N.J.: Associated University Presses, 1995), 9-21.

10. Patti M. Valkenburg and Joanne Cantor, "Children's Likes and Dislikes of Entertainment Programs," in Media Entertainment: The Psychology of Its Appeal, ed. Dolf Zillman and Peter Vorderer (Mahwah, N.J.: Lawrence Erlbaum Associates, 2000), 135-52.

11. Sandra L. Calvert and Jennifer A. Kotler, "Lessons from Children's Television: The Impact of the Children's Television Act on Children's Learning," Journal of Applied Developmental Psychology 24, no. 3 (2003): 275-335, and critical responses in this same special issue.

12. Richard L. Ingersoll and Judith B. Kase, "Effects of Others on the Enjoyment of Live Theatre: A Study of Fourth and Fifth Grade Children," New England Theatre 1, no. 1 (1969): 38-44. More girls than boys tend to enroll in drama classes at youth theatres and high schools.

13. Susanne K. Langer, Philosophy in a New Key (Cambridge, Mass.: Harvard University Press, 1942), 149.

14. For details on imagination, see Helane S. Rosenberg, Creative Drama and Imagination: Transforming Ideas into Action (New York: Holt, Rinehart and Winston, 1987), 49-67.

15. For example, asking first- through third-graders to re-dramatize performances with actor "dolls" and small scenic models provides rich, open-ended data for free story recall.

16. See Judith Van Evra's interactive model of media effects, which includes access to alternative sources of information, in her third edition of Television and Child Development (Mahwah, N.J.: Lawrence Erlbaum Associates, 2004), 18.

17. Howard Gardner, Frames of Mind: The Theory of Multiple Intelligences (New York: Basic Books, 1983), 303-20; and The Unschooled Mind (New York: Basic Books, 1991), 107-9. See also Jean Matter Mandler, Stories, Scripts, and Scenes: Aspects of Schema Theory (Hillsdale, N.J.: Lawrence Erlbaum Associates, 1984).

18. Alan M. Rubin, "Media Uses and Effects: A Uses-and-Gratifications Perspective," in Media Effects: Advances in Theory and Research, ed. Jennings Bryant and Dolf Zillman (Hillsdale, N.J.: Lawrence Erlbaum Associates, 1994), 417-36.

19. Johnny Saldaña, “'Is Theatre Necessary?': Final Exit Interviews with Sixth Grade Participants from the ASU Longitudinal Study," Youth Theatre Journal 9 (1995): 23-25.

20. Jeanne Klein, "Elementary Teachers' Evaluations of University Performances for Young Audiences," Youth Theatre Journal 11 (1997): 1-14.

21. Dolf Zillman, "Mood Management through Communication Choices," American Behavioral Scientist 31 (1988): 327-40; but see Peter Vorderer and Silvia Knobloch, "Conflict and Suspense in Drama," in Media Entertainment, ed. Dolf Zillman and Peter Vorderer (Mahwah, N.J.: Lawrence Erlbaum Associates, 2000), 65-70, for a critique of this theory.

22. Gavriel Salomon, "Television is 'Easy' and Print is 'Tough': The Differential Investment of Mental Effort in Learning as a Function of Perceptions and Attributions," Journal of Educational Psychology 76, no. 4 (1984): 647-58; and Gavriel Salomon and Tamar Leigh, "Predispositions about Learning from Print and Television," Journal of Communication 34, no. 2 (1984): 119-35.

23. For these reasons, all my reception studies have employed original plays, and teachers have been instructed not to use study guides before post-performance interviews to ensure that all interpretations come from the stimulus production alone. Students have also been asked their previous familiarity with or knowledge of play content for comparative purposes. Although I provide teachers with study guides for every production as they've come to expect, I actually hate them, because I personally want theatre to astonish me (" tonnez-moi! "-Diaghilev). 
Instead, I believe that all understanding should come from the production itself and not from a study guide.

24. Jeanne Klein, "Children's Processing of Theatre as a Function of Verbal and Visual Recall," Youth Theatre Journal 2, no. 1 (1987): 9-13; and Jeanne Klein and Marguerite Fitch, "Third Grade Children's Verbal and Visual Recall of Monkey, Monkey," Youth Theatre Journal 4, no. 2 (1989): 9-15.

25. See the complete figure in Mabel Rice, Aletha C. Huston, and John C. Wright, "The Forms of Television: Effects on Children's Attention, Comprehension and Social Behavior," in Children and the Formal Features of Television, ed. Manfred Meyer (New York: Saur, 1983), 38.

26. Jeanne Klein and Marguerite Fitch, "First Grade Children's Comprehension of Noodle Doodle Box," Youth Theatre Journal 5, no. 2 (1990): 7-13.

27. See a table of developmental trends in Paul van den Broek, "Discovering the Cement of the Universe: The Development of Event Comprehension from Childhood to Adulthood," in Developmental Spans in Event Comprehension and Representation, ed. Paul W. van den Broek, Patricia J. Bauer, and Tammy Bourg (Mahwah, N.J.: Lawrence Erlbaum Associates, 1997), 335.

28. John C. Wright Aletha C. Huston, Rhonda P. Ross, Sandra L. Calvert, David Rollandeli, Lee Ann Weeks, Pouran Raessi, and Richard Potts, "Pace and Continuity of Television Programs: Effects on Children's Attention and Comprehension," Developmental Psychology 20, no. 4 (1984): 653-66; and W. Andrew Collins, "Interpretation and Inference in Children's Television Viewing," in Children s Understanding of Television, ed. Jennings Bryant and Daniel R. Anderson (New York: Academic Press, 1983), 125-50.

29. Susanne K. Langer, Feeling and Form (New York: Scribner, 1953), 316-24.

30. Parsons, How We Understand Art; Hope Kelly, "Reasoning about Realities: Children's Evaluations of Television and Books," in Viewing Children through Television, ed. Hope Kelly and Howard Gardner (San Francisco: Jossey-Bass, 1981): 59-71; and Marguerite Fitch, Aletha C. Huston, and John C. Wright, "From Television Forms to Genre Schemata: Children's Perceptions of Television Reality," in Children and Television: Images in a Changing Sociocultural World, ed. Gordon L. Berry and Joy Keiko Asamen (Newbury Park, Calif.: Sage Publications, 1993), 38-52.

31. Jeanne Klein, "Applying Research to Practice: This Is Not a Pipe Dream," Youth Theatre Journal 7, no. 3 (1993): 13-17.

32. Goldberg, Children s Theatre, 92-95.

33. Albert Bandura, "Social Cognitive Theory of Mass Communication," in Media Effects: Advances in Theory and Research, ed. Jennings Bryant and Dolf Zillman (Hillsdale, N.J.: Lawrence Erlbaum Associates, 1994), 61-90.

34. Erica Weintraub Austin, "Effects of Family Communication on Children's Interpretation of Television," in Television and the American Family, $2^{\mathrm{d}}$ ed., ed. Jennings Bryant and J. Alison Bryant (Mahwah, N.J.: Lawrence Erlbaum Associates, 2001), 377-395.

35. Susan Harter, The Construction of the Self: A Developmental Perspective (New York: Guilford Press, 1999), 6-7, 36, 169-71.

36. Jeanne Klein, "Reading Empathy in a Québécois Play: Crying to Laugh," Theatre Research in Canada 15, no. 1 (1994): 58-74.

37. Carol Gilligan and Grant Wiggins, "The Origins of Morality in Early Childhood Relationships," in Mapping the Moral Domain, ed. Carol Gilligan, Janie Victoria Ward, and Jill McLean Taylor (Cambridge, Mass.: Harvard University Press, 1988), 111-38.

38. Compare the following with Saldaña, "'Significant Differences,'" and Anna Mikhailova, "Addressing the Myths and Realities of Age in a Russian Theatre Study," Youth Theatre Journal 8, no. 4 (1994): 7-13.

39. Nancy Eisenberg, The Caring Child (Cambridge, Mass.: Harvard University Press, 1992), 31-32; and Carolyn Saarni, The Development of Emotional Competence (New York: Guilford Press, 1999), 18-19. 
40. Gavriel Salomon and David N. Perkins, "Rocky Roads to Transfer: Rethinking Mechanisms of a Neglected Phenomenon," Educational Psychologist 24, no. 2 (1989): 113-42.

41. Victoria J. Rideout, Ulla G. Foehr, Donald F. Roberts, and Mollyann Brodie, Kids and Media at the New Millennium (Menlo Park, Calif.: Kaiser Family Foundation, 1999).

42. National Endowment for the Arts, 2002 Survey of Public Participation in the Arts, Rpt. 45 (Fall 2003); American Participation in Theatre, Rpt. 35 (Santa Ana, Calif.: Seven Locks Press, 1992), 11; and Richard A. Peterson, Darren E. Sherkat, Judith Huggins Balfe, and Rolf Meyersohn, Age and Arts Participation with a Focus on Baby Boom Cohorts, Rpt. 34 (Santa Ana, Calif.: Seven Locks Press, 1996), 3, 23.

43. David Kilpatrick, "Dancing with Schools: Statistics on the Relationship between School and Public Performances in Selected ASSITEJ/USA Theatres," TYA Today 18, no. 2 (2004): 6-13.

44. See annual attendance figures in the 2004-2005 ASSITEJ/USA Marquee.

45. Davida Bloom, "Selecting the Season: How Do They Do It?" Stage of the Art 8, no. 3 (1996): 12-14.

46. For example, see David Wood, "The Nature of the Beasts," in Theatre for Children (London: Faber and Faber, 1997), 15-61; and Viveka Hagnell, "Children as Spectators: Audience Research in Children's Theatre," in New Directions in Audience Research, ed. Willmar Sauter (Utrecht: International Federation of Theatre Research, 1988), 53-62.

47. For example, see Mark Lutwak, "Guest Editorial," TYA Today 18, no. 2 (2004): 2. 